\title{
Nielen bocianológ Miroslav Fulín jubiluje
}

\section{Not only stork-specialist Miroslav Fulín celebrates a jubilee}

Krásne 70. narodeniny oslávil náš kolega, priatel' a skvelý kamarát Miro Fulín (obr. 1, 2). Zanietený ochranca prírody, ktorého asi najviac poznáme ako prírodovedca, múzejníka, ale hlavne gestora ochrany a monitoringu bociana bieleho na Slovensku. S Mirom Fulínom som sa po prvýkrát stretol v Sabinove na dvore jeho rodičovského domu v roku 2001, spolu s kolegami, ktorí pripravovali výskum netopierov na východnom Slovensku. Každé stretnutie s Mirom je pre mňa taký malý sviatok. Energia, ktorú vyžaruje je, dá sa povedat', až „,nákazlivá“", hned' začnem pocit'ovat', že by som mal niečo zmysluplné robit' pre ochranu prírody.

Miroslav Fulín sa narodil 10. júna 1951 v Prešove do učitel'skej rodiny; detstvo prežil v Sabinove. Už ako diet'a zvedavo prejavil záujem o prírodu a jej tajomstvá. V 13-tich rokoch viedol svoj prvý prírodovedný zápisník a jeho vzorom bol zoológ, ornitológ a ochranca prírody RNDr. Jozef Voskár. Stredoškolské vzdelanie absolvoval na gymnáziu v Sabinove. Ďalej pokračoval vo vysokoškolskom štúdiu s učitel'ským zameraním v odbore biológiachémia na Univerzite Pavla Jozefa Šafárika (UPJŠ) v Košiciach, ktoré ukončil štátnou skúškou v roku 1974. Následne začal pracovat' na Katedre geológie a mineralógie Baníckej fakulty Vysokej školy technickej (VŠT), tiež v Košiciach. Tu pôsobil ako odborný asistent v predmetoch mineralógia, paleontológia a historická geológia. V roku 1981 obhájil rigoróznu prácu so zameraním na teóriu vyučovania biológie na UPJŠ a získal titul RNDr. Pôsobenie na Baníckej fakulte VŠT vyústilo v roku 1988 do obhajoby kandidátskej dizertačnej práce v odbore ložiskovej geológie a dosiahol tak aka- demický titul kandidát vied (CSc.). Pracovisko Baníckej fakulty vo funkcii prodekana pre pedagogickú činnost' opustil v roku 1990.

Aktivity nášho jubilanta sú ohromujúce a niekedy až neuveritel'né: Od roku 1991 pracoval ako odborný pracovník vo Východoslovenskom múzeu v Košiciach, preto je mnoho jeho aktivít spätých práve s touto inštitúciou. V prvých rokoch pôsobenia v múzeu bol kustódom paleontologického zbierkového fondu a neskôr prevzal aj zoologický fond. $\mathrm{V}$ rámci odbornej činnosti sa zameral na dokumentáciu paleontologických lokalít bradlového pásma na východnom Slovensku. Z paleontologického výskumu vyniká jeho nález zubov žraloka rodu Sphenodus (Beňatina, okr. Sobrance), nález fosílií morských rýb vo vnútrokarpatskom paleogéne (Bystré, okr. Vranov nad Topl'ou), či popis jednej z mála známych lokalít s výskytom marmarošských diamantov v Spišskej Magure (Vel'ký Lipník, okr. Stará L’ubovňa). Vo výstavnej a expozičnej práci v múzeu presadzoval ekologické zásady prezentácie exponátov. Je spoluautorom stálej prírodovednej expozície „Príroda Karpát“. Vytvoril 14 autorských výstav a ako spoluautor sa podiel'al na spracovaní 31 výstav.

$\mathrm{V}$ rámci práce $\mathrm{v}$ múzeu sa venoval aj ochrane a monitoringu bociana bieleho, ktorý ešte stále každoročne koordinuje a cez svojich spolupracovníkov - dobrovol'níkov - aj realizuje sčítanie hniezd a mlád'at na celom území Slovenska. S podporou spolupracovníkov z múzea koordinoval v rokoch $2001-2021$ ekovýchovný program „Bocian“ pre mládež na celom území Slovenska, ktorý d’alej pokra- 

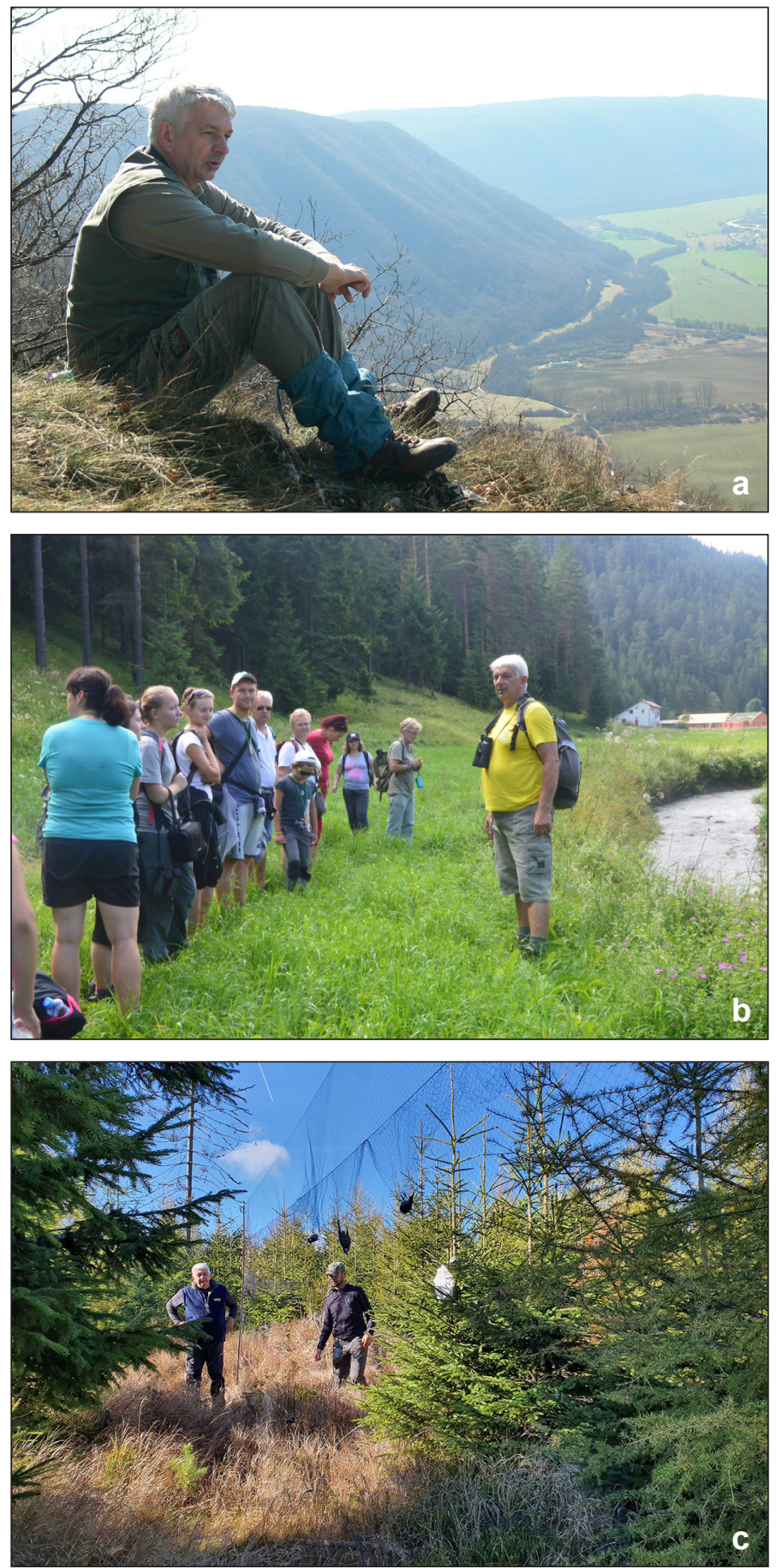

Obr. 1. Miroslav Fulín: v teréne na Brzotínskych skalách, Slovenský kras, 15. 3. 2007 (a); počas Východoslovenského tábora ochrancov prírody, Vernár, Slovenský raj, 26. 7. 2016 (b); odchyt vtákov s M. Revickým pri prameni Torysy, Levočské vrchy, 15. 10. 2021 (c). Foto: E. Sitášová (a), S. Greš (b, c).

Fig. 1. Miroslav Fulín: during the fieldwork at Brzotínske skaly, Slovak Karst, March 15, 2007 (a); during Eastern-Slovakian Camp of Nature Conservationists, Vernár, Slovak Paradise, July 26, 2016 (b); birds' mist-netting with M. Revický at the Torysa river spring, Levočské vrchy Mts, October 15, 2021 (c). Photo by E. Sitášová (a), S. Greš (b, c). 

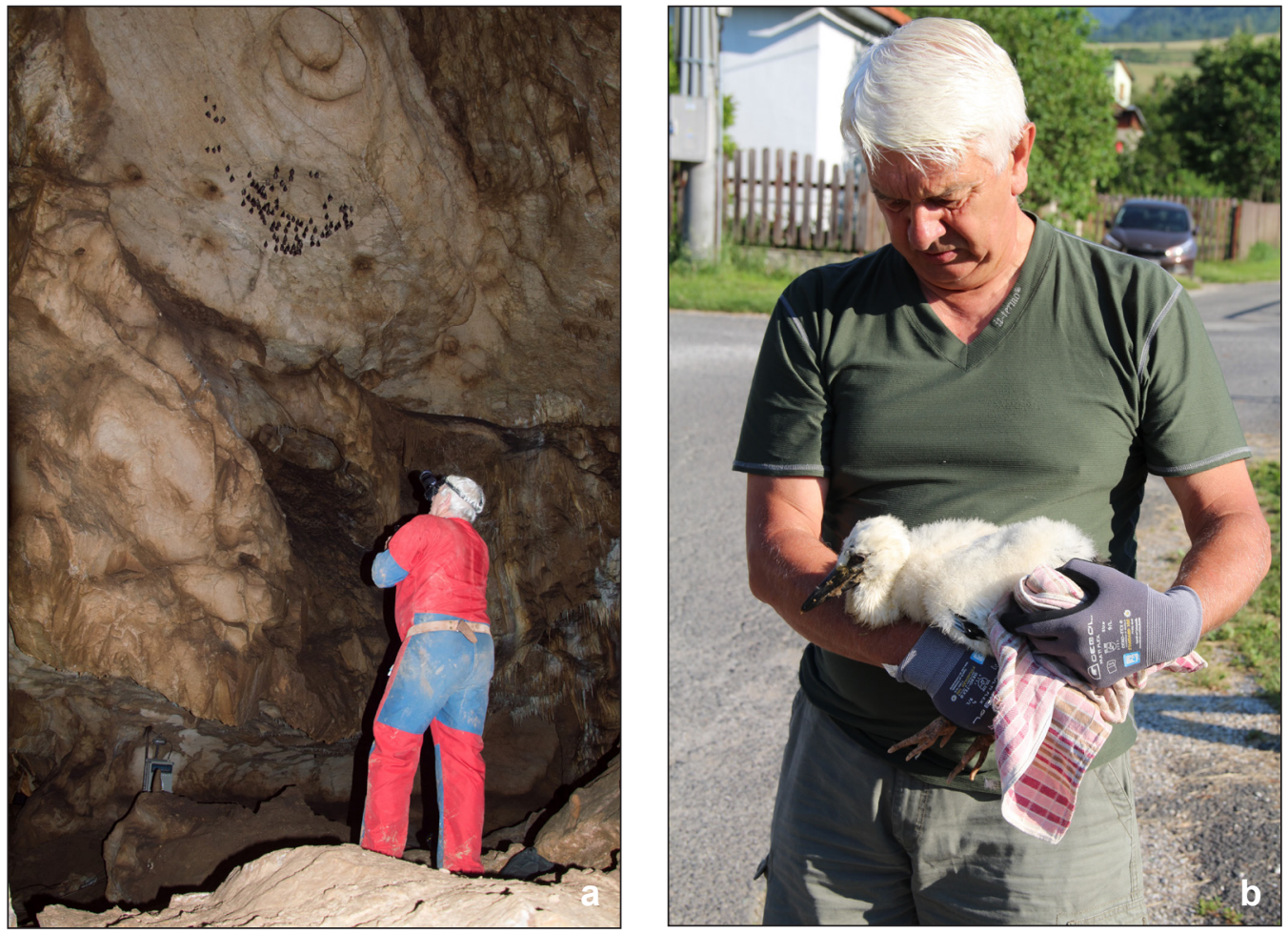

Obr. 2. Miroslav Fulín: sčitanie netopierov v Jasovskej jaskyni, 31. 12. 2019 (a); krúžkovanie bocianov v Kluknave, 6. 7. 2020 (b). Foto: S. Greš (a), V. Kíč (b).

Fig. 2. Miroslav Fulín: bat monitoring in Jasovská jaskyňa Cave, December 31, 2019 (a); stork ringing in Kluknava, July 6, 2020. Photo by S. Greš (a), V. Kíč (b).

čuje pod jeho vedením v spolupráci so Štátnou ochranou prírody SR (ŠOP SR).

Od roku 1994 sa venuje aj monitoringu netopierov (nielen) $\mathrm{v}$ Jasovskej jaskyni. Tu organizuje už viac ako desat' rokov podujatie pre verejnost' zamerané na osvetu a ochranu netopierov pod názvom „Noc netopierov“.

Patrí k zakladatel'om ornitologického stacionára Drienovec (1996). Ako člen tímu krúžkovatel'ov a prírodovedec múzea tu realizoval odchyt a krúžkovanie vtákov, besedy a terénne exkurzie pre širokú verejnost'. Za 25-ročné obdobie aktivít na stacionári okrúžkoval 21568 vtákov. Celkovo doteraz okrúžkoval 63078 jedincov 129-tich vtáčích druhov, z toho 2223 bocianov bielych. Eviduje 6844 spätných hlásení; z toho na bociana 422 .

Od roku 2001 do roku 2017 bol vedeckým redaktorom a zostavovatel'om prírodovedného zborníka Východoslovenského múzea Natura Carpatica a v rokoch 1994 až 2011 člen redakčnej rady časopisu Naturae Tutela, vydávaným Slovenským múzeom ochrany prírody a jaskyniarstva v Liptovskom Mikuláši.

Publikoval viac ako 170 článkov a štúdií v odborných a populárno-náučných periodikách (príloha 1, elektronická príloha 1). Výsledky odbornej činnosti prezentoval vystúpeniami na viac ako 50 domácich a zahraničných konferenciách a seminároch. Spracoval scenár a komentáre pre štyri krátke filmy Slovenskej televízie. Je autorom a spoluautorom deviatich prírodovedných náučných chodníkov (najmä v okolí Košíc, ale aj pri Slánskej Hute, Juskovej Voli a Zámutove, Buzici a Sabinove). Bol spoluriešitel'om $\mathrm{v}$ troch projektoch $\mathrm{v}$ rámci cezhraničnej spolupráce s Mad'arskom a Ukrajinou. Od roku 1971 je členom Slovenského zväzu ochrancov 
prírody a krajiny (SZOPK), pričom v rokoch 1993 - 1997 bol predsedom jeho Ústredného výboru a v roku 1993 bol spoluzakladatel'om Základnej organizácie SZOPK Bocian.

$\mathrm{V}$ roku $2005 \mathrm{mu}$ bolo mestom Moldava nad Bodvou, kde dlhé roky býval, udelené vyznamenanie Cena Pro Urbe za vedeckú činnost', popularizáciu a aktívnu ochranu prírody a krajiny. V roku 2015 mu bola udelená pamätná medaila Zväzu múzeí na Slovensku za výsledky v prezentácii slovenského prírodovedného múzejníctva. Za svoju celoživotnú činnost' a prínos v oblasti múzejníctva bol Miro v roku 2017 ocenený Ministerstvom kultúry Cenou Andrej Kmeta. V roku 2017 získal aj Cenu mesta Sabinov za prínos pri popularizácii ochrany prírody. Za jeho aktivity ho ocenili aj Ministerstvo životného prostredia SR (2019), Štátna ochrana prírody SR (2021), Asociácia strážcov chránených území (2021) a iní.

Mal som štastie a od roku 2008 som sa aj ja pridal do kolektívu prírodovedného odboru vo Východoslovenskom múzeu v Košiciach. Náš kamarátsky vzt’ah sa rozšíril aj o kolegiálny vzt'ah. Ako kolega bol Miro vždy ochotný pomôct' a poradit'. Pracovali sme spolu až do roku 2019, kedy Miro odišiel do dôchodku. Každý by si myslel, že v tomto veku už človek zvykne, ako sa hovorí, „ubrat'“. Miro, naopak, plný energie pracuje na d'alších výskumoch, mapovaniach, pokračuje v spoluorganizovaní Východoslovenských táborov ochrancov prírody (od roku 1991) a venuje sa svojej celoživotnej zál'ube, ktorou je ochrana prírody. Pre nás, mladších, je Miro vel'kým vzorom a jeho pracovitost', húževnatost' a entuziazmus sú neprekonatel'né. Aj z nepríjemnej situácie dokáže Miro vyt'ažit' maximum.

Milý Miro, prajem Ti v d'alších rokoch pevné zdravie a vel’a nových pekných zážitkov, ktoré robia život životom. Vážim si Tvoje priatel'stvo.

Peter Krišovský Východoslovenské múzeum, Košice

Došlo: 23. 2. 2022

Online: 24. 2. 2022

Elektronická príloha je dostupná na webovej stránke časopisu. Online Appendix is available on the journal web page.

Elektronická príloha 1. Bibliografia Miroslava Fulína (do roku 2021 vrátane).

Online Appendix 1. Bibliography of Miroslav Fulin (up to the end of year 2021). 
Príloha 1. Výber z publikácií Miroslava Fulína.

Appendix 1. Selection of Miroslav Fulín's publications.

\section{Články vedecké, populárno-vedecké, odborné štúdie a i. / Articles in journals, newspapers, magazines etc.}

Fulín M. 1972: Neskoré hniezdenie hrdličky záhradnej (Streptopelia decaocto Friv). — Zborník Vsl. Múzea, Košice 11-12, B: 133-134.

Fulín M. 1981: Nezvyčajné hniezdenie bocianov bielych. — Zborník Vsl. Múzea, Košice 22: 217-220.

JACKo S., ZaCharov M., Radzo V. \& FulíN M. 1984: Nález barytového zrudnenia v Čiernej hore. — Mineralia Slovaca 16 (3): 277-282.

Fulín M., FulínOvá J. \& Žolner J. 1984: Lokalita korunkovky strakatej - Fritillaria meleagris L. - v okrese Košice-vidiek. - Pamiatky a príroda 3: 43.

Fulín M. 1984: Straty bocianov bielych (Ciconia ciconia) na hniezdiskách v rokoch 1977 - 1984 vo Východoslovenskom kraji. - Milvus, Zborník VOK 1: 29-35.

Fulín M. \& Žolner J. 1985: Prvé výsledky z krúžkovania strakoša obyčajného (Lanius collurio) pri Moldave n/Bodvou. — Milvus, Zborník VOK, Zemplínske múzeum Michalovce 2: 81-85.

Fulín M. \& Panigaj L. 1985: Niekol'ko poznámok k faune motýl’ov (Lepidoptera) Sabinova a okolia. — Zborník Vsl. múzea, Košice 26: 101-113.

FulíN M. \& ŠTEFFEK J. 1990: Močiar pod Urbárskym lesom nad sútokom Drienovského a Skalitého potoka. —Chránené územia Slovenska 15: 17-20.

Fulín M. \& Žolner J. 1993: Spoločenstvo vtáčích druhov hniezdiacich na juhovýchodnom okraji Slovenského krasu pri Moldave nad Bodvou. — Zborník Vsl. Múzea, Košice 34: 121-128.

FulíN M. ET AL. 1995: Vertebratofauna Hrhovských rybníkov. —- Pp.: 41-46. In: Fulín M. ET AL. (eds.): IUCN: Environmentálno-ekonomické vyhodnotenie funkcií a hospodárenia v rybníkoch na Slovensku. Nadácia IUCN, Bratislava.

Fulín M. \& ŠMELKo Š. 1995: Výskyt vrchárky okrovej (Prunella montanella) v Rožňave. — Natura Carpatica 36: 157-159. Uhrin M., Danko Š., Obuch J., Horáček I., PAČenovský S., PJenČÁK P. \& Fulín M. 1996: Distributional patterns of bats (Mammalia: Chiroptera) in Slovakia. Part 1, Horseshoe bats (Rhinolophidae). — Acta Soc. Zool. Bohem 60: 247-279.

Fulín M. \& Stollmann A. 1996: Populationsuntersuchungen am Weißstorch (Ciconia ciconia) in der Slowakei 1994. — P.: 29. In: Jubiläumsband Weißstorch - Jubilee Edition White Stork Jubilaum 15 Jahre Storchenhof Loburg und 15 Jahre Arbeitskreis Weisstorch 3. Sachsen-Anhaltischer Storchentag vom 21. - 23. 10. 1994 in Loburg.

Fulín M. 1997: Marmarošský diamant pri Vel'kom Lipníku. — Minerál - Svět nerostů a drahých kamenů 5(1): 42-43.

Fulín M. 1998: Obsadenost'vtáčích búdok na juhovýchodnom okraji Slovenského krasu pri Moldave nad Bodvou v rokoch 1980 - 1991. — Natura Carpatica 39: 273-282.

Fulín M. 1998: Doterajšie poznatky o rozmiestnení Rhinolophus ferrumequinum v priestoroch Jasovskej jaskyne počas hibernácie. - Vespertilio 3: 11-18.

Fulín M. 1999: The White Stork in Slovakia in 1994 and 1995. — Pp.: 199-202. In: Schulz H. (ed.): Weisstorch im Aufwind? - White Storks on the up? - Proceedings, Internat. Symp. On the White Stork, Hamburg 1996. - NABU (Naturschutzbund Deutschland e.V.), Bonn.

Matis Š., Danko Š., PJenčÁK P., Uhrin M. \& Fulín M. 2000: Ďalšie poznatky o výskyte netopiera pobrežného (Myotis dasycneme) na Slovensku. - Vespertilio 4: 127-134.

Fulín M. \& Matis Š. 2000: Obsadzovanie jednotlivých priestorov Jasovskej jaskyne (Slovenský kras) podkovárom malým (Rhinolophus hipposideros) počas hibernácie. — Vespertilio 4: 59-66.

Gregorová R. \& Fulín M. 2001: Fosílne ryby vo vnútrokarpatskom paleogéne pri obci Bystré nad Toplou (východné Slovensko). - Natura Carpatica 42: 43-54.

Fulín M. 2001: Ing Aristid Mošanský, CSc. Edícia Medailóny. — Vyd. SNM Bratislava, 36 pp.

Fulín M. 2001: Die Brutpopulation des Weißstorches in der Slowakei 1999. — Pp.: 50-51. In: KaAtz C. \& KaAtz M. (eds.): 2. Jubiläumsband Weißstorch. - 2. Jubilee Edition White Stork. 8 u. 9 Storchentag 1999/2000. Tagungsbandreihe des Storchenhofes Loburg. 
Sitášová E. \& Fulín M. 2001: Možné smery a vývojové trendy múzejnej prezentácie na úseku prírodných vied. — Pp.: 85-88. In: Zborník referátov z odb. konferencie Úlohy prírodných vied v muzealizácii životného prostredia na Slovensku. SMOPaJ Liptovský Mikuláš.

Fulín M. \& Gregor J. 2002: Obojživelníky (Amphiibia) a plazy (Reptilia). — Pp.: 81-83. In: PanigaJ L'. (ed.): Pieniny. Príroda a človek. ŠOP SR S-PIENAP, Červený Kláštor.

Mošanský L., Spalek L., TurČek I. \& Fulín M. 2002: Vtáky (Aves). — In: Panigaj L'. (ed.): Pieniny. Príroda a človek. ŠOP SR S-PIENAP, Červený Kláštor.

Fulín M. 2003: Stromové hniezda vrabca domáceho (Passer domesticus) v Moldave nad Bodvou. — Natura Carpatica 44: $289-290$.

Fulín M. \& Holec P. 2005: Poznámky k fosílnym spoločenstvám v bradle pri Beňatine. — Mineralia Slovaca 37(3): 321-323.

Holec P, SÝKora M. \& Fulín M. 2005: Sphenodus sp. (Chondrichthyes, Vertebrata) z mezozoika niektorých lokalít na Slovensku. - Mineralia Slovaca 37: 555-558.

Słther B. E., Grøtan V., Tryjanowski P., Barbraud C., Engen S. \& Fulín M. 2006: Climate and spatio-temporal variation in the population dynamics of a long distance migrant, the White Stork. — Journal of Animal Ecology 75: 80-90.

Kaňuch P., Pavúk J., Sárossy M., Fecko M., Fulín M., Imrich P., Krišovský P., Olejár I., Sedlák M. \& Vrábel P. 2006: Torysa - migračná cesta vtáctva po 40 rokoch. - Tichodroma 18: 31-42.

Fulín M. \& Matis Š. 2006: Výsledky výskumu netopierov (Chiroptera) v Jasovskej jaskyni v rokoch 1996 - 2006. — Natura Carpatica 47: 187-196.

Fulín M. 2007: Tretí výskyt kolibkárika žltkastotemenného (Phylloscopus inornatus, Blyth) na Slovensku. — Natura Carpatica 48: 205-206.

Fulín M. \& Sitášová E. 2007: Fauna a flóra gemerskej časti Bodvianskej pahorkatiny. — Gemer-Malohont, Zborník Gemersko-malohontského múzea v Rimavskej Sobote 3: 10-18.

Fulín M. \& Holec P. 2008: Nález vtáčej nohy (Aves) v paleogénnych sedimentoch lokality Bystré nad Toplou. — Mineralia Slovaka 40: 183-184.

FulíN M. 2008: Inventarizačný prieskum výskytu druhu Sadleriana pannonica (Frauenfeld, 1865) na vybraných lokalitách národného parku Slovenský kras. — Pp.: 133-140. Biosferické rezervácie na Slovensku VII. Zborník referátov. VYDAVATEL', MESTO.

FulíN M. \& OLEKŠÁK M. 2009: Zaujímavé ornitologické pozorovania z rybničných sústav Turnianskej a Košickej kotliny (V Slovensko). — Tichodroma 21: 108-110.

Fulín M., Jerzak L., Sparks H. T. \& Tryjanowski P. 2009: Relationship between arrival date, hatching date and breeding success of the white stork (Ciconia ciconia) in Slovakia. - Biologia 64: 361-364.

BačKor P., Bobáková L., Fulín M., Lehotská B., Lehotský R., Uhrin M. \& Višňovská Z. 2011: Trend početnosti netopierov zimujúcich vo vybraných sprístupnených jaskyniach na Slovensku. — Pp.: 24-25. In: BRYJA J., ŘEHÁK Z. \& ZuKal J. (eds.): Zoologické dny Brno 2011. Sborník abstraktů z konference 17.-18. února 2011. Ústav biologie obratlovců AV ČR, Brno.

Fulín M. 2011: Kameňolomy a ich fauna. — Natura Carpatica 52: 111-128.

Uhrin M., Boldogh S., Bücs Sz., Paunovics M., Miková E., Juhász M., Csösz I., Estók P., Fulín M., Gombkötö P., Jére Cs. Barti L., Karapandža B., Matis Š., Nagy Z., Szodoray-PÁradi F. \& Benda P. 2012: Revision of the occurrence of Rhinolophus euryale in the Carpathian region, Central Europe. - Vespertilio 16: 289-232.

FuLín M. 2012: Úskalia súčasnej tvorby prírodovedných zbierok v múzeách na Slovensku. — Múzeum 2012/3: 53-54.

SEČAnSKÝ M. \& Fulín M. 2013: Myš kopčiarka (Mus spicilegus) pri Drienovci (okres Košice-okolie). — Natura Carpatica 54: 119-120.

Gordo O., Tryjanowski P., Kosicki Z. J. \& Fulín M. 2013: Complex phenological changes and their consequences in the breeding success of a migratory bird, the white stork (Ciconia ciconia). — Journal of Animal Ecology 82: 1072-1086. 
Príloha 1. Pokračovanie.

Appendix 1. Continuation.

Fulín M. \& KRIŠOvskÝ P. 2014: Rybníky pri Uzovskom Šalgove - významné nocovisko migrujúcich lastovičiek obyčajných (Hirundo rustica) v Šarišskej vrchovine. - Pp.: 67-69. Manko P. \& Baranová B. (eds.): Zborník príspevkov z vedeckého kongresu Zoológia 2014, 19. Feriancove dni 20. - 22. november 2014. Vydavatel'stvo Prešovskej univerzity, Prešov.

Fulín M. \& RevickÝ M. 2015: Avifauna východnej časti Levočských vrchov (V Slovensko). — Tichodroma 27: 53-74.

Fulín M. 2015: Označovanie bociana bieleho (Ciconia ciconia) na Slovensku - stav vedenia záznamov a evidencie spätných hlásení. - Tichodroma 27: 100-106.

Fulín M. 2016: Oologická zbierka J. Suváka z Čečejoviec. — Natura Carpatica 57: 103-114.

FulíN M. \& OLEKŠÁK M. 2017: K migrácii a zimným nocoviskám piniek severských (Fringilla montifringilla) na Slovensku. - Tichodroma 29: 16-24.

Fulín M. \& SitÁšová E. 2017: Zmeny v krajine a ich vplyv na rôznorodost' druhov v katastrálnom území obce Buzica (okres Košice-okolie). — Natura Carpatica 58: 55-76.

Fulín M., KrišovskÝ P. \& GREŠ S. 2017: Kríženec belorítky obyčajnej (Delichon urbicum) a lastovičky obyčajnej (Hirundo rustica). — Natura Carpatica 58: 139-142.

Fulín M. 2018: Hniezdne spoločenstvá vtáčích druhov v intraviláne obce Tichý Potok (Okres Sabinov). — Natura Carpatica 59: 17-24.

Fulín M. 2018: Štyridsat’ rokov života s bocianmi. — Natura Carpatica 59: 97-108.

Fulín M., RevickÝ M. \& GReŠ S. 2018: Vodnár potočný (Cinclus cinclus) na hornej Toryse. — Spiš. Vlastivedný zborník 9: 408-415.

Fulín M. 2019: Hniezda bociana bieleho na stípoch elektrického vedenia. — Chránené územia Slovenska 91: 12-21.

Nusová G., Fulín M., Uhrin M., Uhrovič D. \& KAŇUCH P. 2019: Spatiotemporal pattern in the autumn invasion behaviour of the common pipistrelle, Pipistrellus pipistrellus: Review with a case study. — Mammalian Biology 97: 13-21.

Divok F., Fulín M. \& Kautman J. 2020: Príspevok k poznaniu rozšírenia obojživelníkov a plazov v Levočských vrchoch. - Spiš. Vlastivedný zborník 10: 325-346.

Fulín M., GREŠ S., KRIŠOvSKÝ P., MiŠEK T. \& JARČUŠKA B. 2020: Hniezdne spoločenstvá vtákov vo vzt’ahu k štruktúre urbánneho prostredia malého mesta (Sabinov, východné Slovensko). — Tichodroma 32: 1-18.

Fulín M., KĹČ V., SPAleK L., TurČEK I. \& KunŠTÁRová KlČOvá V. 2020: Avifauna západnej časti Levočských vrchov (Východné Slovensko). — Spiš. Vlastivedný zborník 10: 347-367.

JARČUŠKa B., KĹČ V., KunŠTÁrovÁ KĹČová V. \& FulíN M. 2020: K výskytu bobra euroázijského (Castor fiber) v Levočských vrchoch. - Spiš. Vlastivedný zborník 10: 394-403.

Fulín M. \& SitÁšová E. 2020: Kam smerujú prírodné vedy v múzeách. — Múzeum 2020/2: 10-11.

\section{Nepublikovaný materiál / Unpublished material}

FuLín M. 1974: Vertebratofauna ŠPR Šarišský hradný vrch. — Diplomová práca. Knižnica PF UPJŠ Košice, 52 pp.

Rozložník L., ZaCharov M., Fulín M., ZÁBranský F. \& Radzo V. 1982: Geologicko-štruktúrne pomery Jasovskej skaly a analýza recentných deformácií v Jasovskej jaskyni. — Záverečná správa, KGaM BF VŠT Košice pre ÚŠOP, MSK Liptovský Mikuláš.

JACKO S., Fulín M. \& ZACHAROv M. 1984: Štruktúrne-metalogenetická štúdia Braniska a Čiernej hory. —Záverečná správa pre GP, n. p. Spišská Nová Ves. Manuskript - archív GP.

Fulín M. 1988: Šlichová prospekcia Braniska a Čiernej hory. Kandidátska dizertačná práca. — Kat. geológie a mineralógie BF VŠT Košice.

Bobáková L., Brinzík M., Danko Š., Fulín M., Hapl E., Hájek B., Lehotská B., Lehotský R., Matis Š., Obuch J., PJENČÁK P. \& UHrin M. 2002: Čiastkový monitorovací systém (ČMS) BIOTA čast' netopiere. Záverečná správa za rok 2002. 10 pp. [Depon. in Spoločnost' pre ochranu netopierov na Slovensku]

\section{Editor}

Fulín M. 2009: Prírodovední pracovníci v múzeách Košického kraja. — ZO SZOPK Bocian, Moldava nad Bodvou. 